\title{
O humor rabelaisiano de Patrick Chamoiseau e Mário de Andrade
}

\author{
Eurídice Figueiredo
}

Segundo Octavio Paz, a Antigüidade conhecia a comédia e a sátira, mas "a ironia e o humor são a grande invenção do espírito moderno"*. O fundamento do romance moderno, que nasce com Rabelais e Cervantes, é justamente o humor, gerador de toda a sua ambigüidade. Assim Quixote e Sancho, Pantagruel e Panurge, combinam o sério e o cômico, o real e o fantástico, a razão e a loucura, o sublime e o grotesco. Bakhtin, entretanto, fala da "solidão particular de Rabelais" na tradição literária que se seguiu: "impossível chegar a ele seguindo os caminhos que a criação artística e o pensamento ideológico da Europa burguesa adotaram nos quatro séculos que o separam de nós"*.

É somente no século XX e fora da Europa, especialmente nos países da América Latina e do Caribe, em regiões onde as tradições orais e folclóricas ainda estavam vivas, que alguns romancistas reatam com o realismo grotesco de Rabelais, dando um salto de séculos. De fato, a herança cômica de Rabelais é muito evidente na obra do brasileiro Mário de Andrade, autor de Macunaíma (1928), e na do martiniquense Patrick Chamoiseau, cujo primeiro romance é Chroniques des sept misères (1986). Nos romances desses autores, pode-se observar determinados procedimentos inventariados e analisados por Mikhaïl Bakhtin a propósito da obra de Rabelais: realismo grotesco que privilegia as ações ligadas ao baixo ventre (digestivo e sexual), uso de hipérbole e de enumerações, contato direto com o leitor, utilização de contos populares, recursos à oralidade, jogos de linguagem e emprego de apelidos para designar os personagens.

Para destacar essa nova floração do romance fora da Europa, Milan Kundera prefere falar, de modo geral, do "romance que está abaixo do trigésimo quinto paralelo, ou do romance do Sul: uma nova e importante cultura romanesca caracterizada por um extraordinário senso do real ligado a uma imaginação desmedida que ultrapassa todas as regras

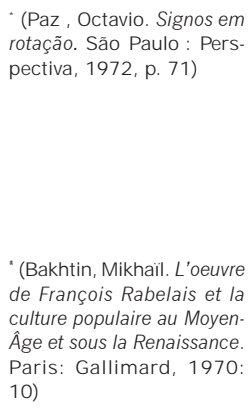


* (Kundera, Milan. Testaments trahis. Paris: Gallimard, 1993: 43)

${ }^{*}(: 45)$

* (Ménil, René. "L'humour: introduction à 1945". Em: Tracées: identité, négritude, esthétique aux Antilles. Paris: Robert Laffont, 1981: 134) da verossimilhança" ${ }^{*}$. Segundo Kundera, "embora um pouco estranha para o gosto europeu [ ...] em nenhuma outra parte a velha seiva rabelaisiana flui, nos dias de hoje, tão alegremente quanto nas obras de romancistas não europeus"* .

Com efeito, os escritores da América Latina e do Caribe, sobretudo a partir dos anos 1920, romperam com as estéticas retardatárias do naturalismo, do simbolismo e do parnaso ainda em vigor, e aderiram a diferentes vanguardas: futurismo, dada, esprit nouveau, surrealismo. A revolução artística que se produz conduz à negritude cesairiana, aos diferentes indigenismos, ao modernismo brasileiro, e termina, nos anos 1960, com o boom do romance hispano-americano. O Caribe francófono se insere nesse contexto de produção porque os escritores sofrem as mesmas influências da realidade social, política e cultural, sem falar dos contatos e da interlocução com seus pares, independentemente da língua em que escrevem. O humor que surge com as vanguardas - humor negro, paródia, carnavalização - é compartilhado por um grande número de escritores deste lado do Atlântico.

René Ménil, cuja expressão "o riso amargo" é retomada por Patrick Chamoiseau em Solibo magnifique, considera que "o humor é um protesto contra nossa falta de autoridade e uma defesa contra as sensações dolorosas e desagradáveis que resultam das limitações que os homens, as coisas ou o acaso impõem à nossa dignidade nativa"*. Fora de contexto, essa afirmação poderia ser compreendida em um quadro unicamente individual, mas a abordagem marxista do autor conduz à leitura para uma perspectiva histórica da América como um continente que resultou de um processo colonial. O humor de que fala Ménil seria a resposta do colonizado humilhado a uma situação de opressão. Assim, destaca o humor dos poetas da negritude, que deste se servem como um meio de recuperar de forma imaginária a dignidade ultrajada. À guisa de exemplo, cita alguns versos de Aimé Césaire em Cahier d'un retour au pays natal:

\footnotetext{
${ }^{1}$ Sem querer questionar a pertinência e a acuidade de Kundera, que fala de romance do Sul, eu diria que talvez a categoria não se devesse definir em termos geograficamente determinados Norte-Sul, pois o Sul compreende um mundo enorme e disparatado que não produz forçosamente o mesmo tipo de literatura. Antonine Maillet, que recebeu o prêmio Goncourt com Pélagie-la-Charrette em 1979 (Montréal: Bibliothèque Québécoise, 1990), embora venha do Norte (Canadá), insere-se em uma estética rabelaisiana.
} 
E já que jurei nada esconder de nossa história, [...] devo confessar que fomos desde sempre pífios lavadores de pratos, engraxates sem envergadura, fomos, no máximo, feiticeiros bastante conscienciosos e o único recorde que batemos foi o de resistência ao chicote...
Et puisque j’ai juré de ne rien celer de notre histoire [...], je veux avouer que nous fûmes de tout temps d'assez piètres laveurs de vaisselle, des cireurs de chaussures sans envergure, mettons les choses au mieux, d'assez consciencieux sorciers et le seul indiscutable record que nous ayons battu est celui d'endurance à la chicotte... ${ }^{*}$.

A análise de Ménil, segundo a qual "o humorista zomba e não ri” *, aplica-se com perfeição ao humor cáustico de Césaire, que o utiliza para atacar o colonialismo e a escravidão. A pergunta de Ménil a respeito desse tipo de humor é provocadora: "Vemos muitas vezes que o humor é uma arma que dispara. Mas contra quem é preciso apontá-la? Este gesto seria contra si mesmo?” *. Sem chegar a afirmar que esse humor é suicida, é forçoso constatar que, para transgredir a ordem estabelecida, o humor cesairiano reafirma todos os clichês sobre os negros criados pelos brancos, de maneira que a representação estereotipada repetida por um poeta negro funciona como um bumerangue que se volta contra o opressor:

eu declaro meus crimes e não há nada a dizer em minha defesa. je déclare mes crimes et qu'il y a rien à dire pour ma défense.

Danças. Ídolos. Relapso. Eu também Danses. Idoles. Relaps. Moi aussi

Assassinei Deus com minha preguiça com minhas palavras com [meus gestos com minhas canções obscenas [...] J'ai assassiné Dieu de ma paresse de mes paroles des mes gestes des mes chansons obscènes [...].

A extensão de minha perversidade me confunde. L'étendue de ma pervesité me confond. *

O poeta, em uma inversão bem ao gosto surrealista, reafirma tudo aquilo que os antigos senhores diziam sobre os negros, e recria a situação ao modo do psicodrama, forçando o reconhecimento dos antigos crimes praticados durante a escravidão, para, assim, apagar da história a abjeção a que os negros tinham sido relegados.

De modo similar, mas em registro mais paródico e carnavalizado, pode-se mencionar Manifesto antropófago, texto de

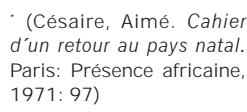

*(Ménil, René. “L'humour: introduction à 1945". Ob. cit.: 134)

* (: 139)
* Césaire, Aimé. Cahier d'un retour au pays natal. Ob. cit: 77) 
(Chamoiseau, Patrick. "En témoignage d'une volupté", Carbet, n. 10 Cheminements et destins dans I'oeuvre d'Edouard Glissant, Fort-de-France décembre 1990: 151)
Oswald de Andrade de 1928, em que cita Shakespeare de forma transgressiva, "Tupi or not Tupi, that is the question", e que se traduziria por: se os brasileiros são descendentes dos tupis, que eram canibais segundo a crônica e a iconografia existentes, é preciso reforçar parodicamente o clichê e reivindicar a antropofagia como marca nacional. Em termos mais alegóricos, a explicação se refere à maneira com que o brasileiro consome os bens culturais da Europa, digerindo-os, metabolizando-os, transformando-os em algo novo.

Ao contrário do "riso amargo", do humor cortante e intelectual de Césaire, Édouard Glissant introduz na literatura martiniquense o riso alegre de origem popular, o riso simples dos camponeses, como no exemplo dado por Chamoiseau em artigo publicado na revista Carbet." Trata-se de uma cena bufa de Malemort, romance de Glissant, em que um porco sai desembestado e ninguém consegue agarrá-lo. René Ménil, aliás, em seu artigo sobre o humor já citado, e que foi escrito originalmente em 1945 para a revista Tropiques, afirmara que o camponês antilhano tem humor, o que não era o caso da burguesia negra letrada.

Assim, os escritores que se inspiram nesse riso popular, e nos mitos, lendas e contos, estão mais aptos a incorporar o humor rabelaisiano. Ao gozo da carne podem se suceder momentos negativos porque, como diz Bakhtin, a estética do realismo grotesco incorpora o ritmo cíclico da vida, que implica todas as etapas das ações corporais, como a digestão, o ato sexual, o nascimento e a morte. Basta lembrar o nascimento de Gargantua, saído pela orelha de sua mãe, em um capítulo em que todas as funções do ventre entram em ação.

Mário de Andrade encontra o núcleo de sua história, inclusive o nome do herói Macunaíma, em uma coleção de mitos indígenas publicados pelo etnógrafo alemão Koch-Grünberg. $\mathrm{O}$ autor paulista, cujo trabalho incorporou simultaneamente a etnografia, a musicologia e a criação literária, usou material recolhido em outros livros sobre a Amazônia e em suas pesquisas de campo. Patrick Chamoiseau, por sua vez, utilizou as tradições populares, contos e lendas sobre o dorlis, sobre Man Zabyme, sobre a jarra de ouro e sobre o zumbi Afoukal, guardião da jarra de ouro, para criar seu livro Chroniques des sept misères.

Os dois livros se constroem como um mosaico, uma colagem de contos um pouco heteróclitos que adquirem um 
sentido no conjunto da obra. Apesar da nomeação genérica de romance, ambos se distinguem dessa forma canônica devido a esse aspecto de conjunto de contos populares. Em razão de seu caráter oral e cômico, inspirado em cantadores do Nordeste que improvisam seus cantos em forma de duelos verbais, Mário de Andrade considera Macunaíma uma rapsódia. Segundo Gérard Genette, a rapsódia é filha da paródia, e vice-versa, porque os rapsodos gregos, no momento em que cantavam os versos épicos, introduziam, com o fim de entreter a audiência, pequenos poemas compostos com os mesmos versos, mas cujo sentido era alterado. *. O caráter épico e nacional - ainda que de maneira paródica - está presente no projeto literário dos dois autores, estando subjacente no título do livro de Chamoiseau, pois se trata de uma crônica, termo que remete aos cronistas que reproduziam os relatos históricos.

A rapsódia designa também "uma peça de composição muito livre e de inspiração nacional e popular", como define o dicionário Le Petit Robert. O caráter musical é explicitado no fim de Macunaíma, quando o narrador pronuncia suas últimas palavras: "Me acocorei em riba destas folhas, catei meus carrapatos, ponteei na violinha e em toque rasgado botei a boca no mundo cantando na fala impura as frases e os casos de Macunaíma, herói de nossa gente"**.

Chamoiseau, de seu lado, com diferentes alter egos (Oiseau de Cham, Chamzibié), apresenta-se em seus primeiros romances como etnógrafo. Em Solibo magnifique, ele é aquele que continua a tradição oral.

Não, escritor não: escrevinhador, isto muda tudo, inspetor, o escritor é de um outro mundo, ele rumina, elabora ou prospecta, o escrevinhador recusa uma agonia, a da oralitura, ele recolhe e transmite.
Non, pas écrivain: marqueur de paroles, ça change tout, inspectère, l'écrivain est d'un autre monde, il rumine, élabore ou prospecte, le marqueur refuse une agonie: celle de l'oraliture, il recueille et transmet.*

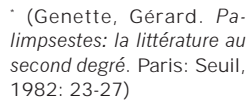

* (Andrade, Mário. Macu naíma: o herói sem nenhum caráter. Edição crítica de Telê Porto Ancona Lopez. Rio de J aneiro / São Paulo Livros Técnicos e Científicos / Secretaria de Cuth

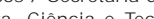
ra, Ciencia e Tecnologia 1978: 148)

Essa oralitura, ou escritura da oralidade, dos dois escritores deve transmitir, como observa Édouard Glissant, um ritmo que não é o da escrita: "na elocução do falar crioulo encontramos a mesma marcação do ritmo do tambor. Não é a estrutura semântica da frase que ajuda a escandir a palavra, é a respiração do locutor que comanda a escansão: atitude de metrificação poética 
* (Glissant, Edouard. Le discours antillais. Paris: Seuil, 1981: 239)

* (Chamoiseau, Patrick \& Confiant, Raphaël. Lettres créoles: tracées antillaises et continentales de la litté rature. 1635-1975. Paris: Hatier, 1991: 190)

" (Andrade, Mário. Macunaíma: o herói sem nenhum caráter. Ob. cit.: 39)

* (Cascudo, Luís da Câmara. Contos tradicionais do Brasil. Rio de J aneiro: Ed. de Ouro, s/d: 250)

* "Le temps passait, passait, passait, il passait tellement que souvent i repassait" (Chamoiseau, Patrick. Chroniques sept misères. Paris: Gallimard, 1986: 193) por excelência”". Ora, considerando que, "em crioulo, 'marquer' significa escrever mas corresponde também a marcar o ritmo no batuque de atabaques (tambours-ka)"* que acompanham o contador de histórias, depreende-se a importância do ritmo musical nessa oralidade apropriada por Chamoiseau.

Essa musicalidade se manifesta também em Macunaíma com muitas expressões rimadas, onomatopéias, aliterações, canções, adivinhações: "Maanape atirava a sarabatana e Macunaíma aparava os macucos macacos micos mutuns jacus jaós tucanos, todas essas caças”*. Em Chroniques, também há algumas canções, mas a maior parte da musicalidade - os gritos do djob, as palavras dos djobeurs ${ }^{2}$, assim como a canção de Kouli - foi eliminada do texto, figurando apenas no fim do livro a partir da segunda edição.

A musicalidade se encontra também nas enumerações, procedimento tipicamente rabelaisiano, cujo caráter é cômico popular. Ancona Lopez sublinha que Mário de Andrade tomou emprestado das narrativas de Koch-Grünberg duas soluções estilísticas fundamentais: a intensidade verbal pela repetição - por exemplo, "Ele se põe a crescer crescer" - e a mistura de elementos disparatados nas enumerações sem pausa, quer dizer, sem vírgula. $\mathrm{O}$ primeiro procedimento é próprio do conto popular e, segundo Cascudo, encontra-se em todo tipo de conto popular", como nesta passagem de Chroniques: "O tempo passava, passava, passava, ele passava tanto que muitas vezes ele repassava"*. A enumeração também é utilizada por Chamoiseau, mas este põe vírgulas entre os termos, como Rabelais, aliás. Essas enumerações hiperbólicas se tornam cômicas graças ao caráter heteróclito, quiçá fantasioso dos materiais listados, muito freqüentemente desconhecidos dos leitores.

Para expulsar o filho indesejável, Pour chasser l'enfant indésiraJoubaré esgotou as reservas de ble, Joubaré épuisa ses réserves óleo de rosa, de óleo dos sete d'huile de rose, d'huile des septs dons, de óleo de Jerusalém e de dons, d'huile de Jérusalem et óleo do Espírito Santo. Ele des- d’huile du Saint Esprit. Il gasperdiçou um pé de galinha preta pilla une patte de poule noire que matou numa sexta-feira, tuée un vendredi, un pétale de

${ }^{2}$ Djobeurs é uma palavra crioula que designa os biscateiros em geral. Neste romance, mais especificamente, refere-se àqueles que carregavam os produtos do mercado em seus carrinhos de mão; djob seria o trabalho. 
uma pétala de flor de bambu, três folhas de raiz forte, três flores de mamão macho, um maço de raiz de capim cheiroso bento, dois copos de leite, quatro cabeças de cobra, e um baita molho de plantas abortivas das mais secretas. Mas o embrião grudou feito o diabo nas entranhas de Clarine. fleur de bambou, trois feuilles de raifort, trois fleurs de papaye male, un paquet béni de racines de vétiver, deux chopines de lait, quatre têtes de serpents, et un bouquet méchant de plantes abortives les plus secrètes. Mais le germe s'accrocha en diable sourd aux entrailles de Clarine *

Os dois autores se inscrevem em uma lógica do realismo mágico, incorporando os contos fantásticos e os contos maravilhosos, e transgredindo, com facilidade, as regras do realismo tradicional. O protagonista de Chamoiseau tem uma história bem fantástica: Pipi, filho de dorlis ${ }^{3}$, consegue falar com o zumbi que guarda o jarro de ouro, mas é morto por Man Zabyme. De maneira análoga, Macunaíma vive em um mundo mágico porque ele se metamorfoseia e tem o poder de transformar os objetos e as pessoas: criança travessa, torna-se príncipe sedutor para fazer amor com suas cunhadas; índio negro, torna-se branco; deixando sua Amazônia natal e chegando a São Paulo, deve lutar contra Venceslau Pietro Pietra, aliás, o gigante Piaimã; transforma o irmão em máquina-telefone para encomendar mulheres e comidas; no fim do romance, decide ir para o céu e virar constelação.

Ambos os romancistas também partilham o realismo grotesco, cujos sinais característicos mais marcantes são, segundo Bakhtin, "o exagero, o hiberbolismo, a profusão, o excesso"*. A gula e a escatologia, principais marcas de Rabelais, também são exploradas. Macunaíma, como Pantagruel, "fez coisas de sarapantar":

Quando era pra dormir trepava no macuru pequeninho sempre se esquecendo de mijar. Como a rede da mãe estava por debaixo do berço, o herói mijava quente na velha, espantando os mosquitos bem. Então adormecia sonhando palavras feias, imoralidades estrambólicas e dava patadas no ar ${ }^{*}$.

${ }^{3} \mathrm{O}$ dorlis designa uma espécie de feiticeiro que consegue penetrar nas casas das moças para fazer amor com elas enquanto dormem. O zumbi, no imaginário antilhano, designa um morto-vivo que não tem vontade própria e está a serviço daquele que o subjugou, geralmente um pai-de-santo do vodu. A Man Zabyme é uma espécie de sereia que seduz os homens, levando-os para dentro d'água, onde os mata.

Eurídice Figueiredo · O HUMOR RABELAISIANO DE PATRICK CHAMOISEAU E MÁRIO DE ANDRADE
(Bakhtin, Mikhaïl. L'oeuvre de François Rabelais et la culture populaire au Moyen Âge et sous la Renaissance. Ob. cit: 302) naíma: o herói sem nenhum caráter. Ob. cit.: 7) 
${ }^{*}(: 66)$

${ }^{*}$ (Chamoiseau, Patrick. Chroniques des sept misè res. Ob. cit: 122)
* (Andrade, Mário. Macunaíma: o herói sem nenhum caráter. Ob. cit.: 62)
Enquanto Chamoiseau utiliza a escatologia de maneira parcimoniosa, Mário de Andrade descreve inúmeros episódios, dos quais se pode citar o do urubu, que faz suas necessidades sobre Macunaíma: "Macunaíma tremia que mais tremia e o urubu sempre fazendo necessidade em riba dele”* Mas, é preciso admitir, ninguém ultrapassa Rabelais em linguagem escatológica e licenciosidade.

O grotesco é criado pelo excesso, presente no episódio do inhame gigante que Pipi consegue transportar: pesando 127 quilos e meio, o inhame, objeto de olhares de admiração, fica exposto ao público e não será comido por ninguém. Podre, tornou-se uma massa cremosa cheia de vermes, que exalava um odor fétido e teve de ser destruído pelo serviço municipal de higiene com lança-chamas. O exagero aparece também no uso de números hiperbólicos, o que é um procedimento bem rabelaisiano. O mulato Zozor Alcide-Victor levava uma vida licenciosa, fonte da infelicidade sentimental de mil oitocentas e sete negras, quatrocentas sararás, seiscentas e cinqüenta mulatas, duas chinesas e toda uma banda de morenas, pardas, branquelas e mamelucas. source du malheur sentimental de mille huit cent sept négresses, quatre cents chabines, six cent cinquante mulâtresses, deux Chinoises, et tout un régiment de câpresses, de quarterons, d'albinos et d'échappées-coulies*
Da mesma forma, acha-se de forma reiterada esse gênero de enumeração em Macunaíma. Na cena da macumba, o exagero dos suplícios infligidos com a ajuda de Exu ao inimigo do herói, o gigante Piaimã, chegaria ao sadismo não fosse o tom paródico que lhe confere comicidade.

Macunaíma ordenou que o eu do gigante fosse tomar banho salgado e fervendo e o corpo de Exu fumegou molhando o terreno. E Macunaíma ordenou que o eu do gigante fosse pisando vidro através dum mato de urtiga e agarra-compadre até as grunhas da serra dos Andes pleno inverno e o corpo de Exu sangrou com lapos de vidro, unhadas de espinhos e queimaduras de urtiga, ofegando de fadiga e tremendo de frio. Era horroroso. E Macunaíma ordenou que o eu de Venceslau Pietro Pietra recebesse o guampaço dum marruá, o coice dum bagual, a dentada dum jacaré e os ferrões de quarenta vezes quarenta mil formigas-de-fogo e o corpo de Exu retorceu sangrando empolando na terra, com uma carreira de dentes numa perna, com quarenta vezes quarenta mil ferroadas de formiga na pele já invisível, com a testa quebrada pelo casco dum bagual e um furo de aspa aguda na barriga. 
Bakhtin destaca a importância do riso como força regeneradora, assim como o são as grosserias, as imprecações e as blasfêmias. O riso "liberta não somente da censura exterior, mas antes de tudo do grande censor interior, o medo do sagrado, da interdição autoritária, do passado, do poder, medo enraizado no espírito do homem há milhares de anos"*. Essa dessacralização tanto do poder religioso quanto do poder político aparece em Chamoiseau e Andrade, quando ridicularizam o status quo por intermédio da inversão de valores. Basta mostrar o exemplo do bar Chez Chinotte, o santuário de uma missa do rum em que se comunga com o primeiro punch. ${ }^{*} \mathrm{Ou}$ ainda o contra-veneno dos antigos amantes de Marguerite Júpiter, amedrontados com uma maldição que teria sido lançada por Pipi: "Eles usavam cuecas molhadas de água benta e, sacrilégio Jesus-Maria-José, um terço amarrado no membro visado"*.

Na cena da macumba em Macunaíma, também existe sacrilégio quando o personagem de Tia Ciata recita "a reza maior do diabo".

Padre Exu achado nosso que vós estais no trezeno inferno da esquerda de baixo, nóis te quereremo muito, nóis tudo! [...] O pai nosso Exu de cada dia nos dai hoje, seja feita vossa vontade assim também no terreiro da sanzala que pertence pro nosso padre Exu, por todo o sempre que assim seja, amém!... *.

No mundo do realismo grotesco e da carnavalização, Macunaíma é o Imperador da Floresta, Pipi é o rei dos Djobeurs, assim com Pantagruel é o rei dos Dipsodos. Esses títulos de realeza funcionam como alcunhas, em combinação com outras: Macunaíma é também o herói sem nenhum caráter, enquanto Pipi é um apelido formado a partir das primeiras sílabas de seu nome: Pierre Philomène (Piphi, que evolui para Pipi). Segundo Bakhtin, "esse nome-alcunha não é jamais neutro porque seu sentido inclui sempre uma idéia de apreciação (positiva ou negativa), é em realidade um brasão"*. Os nomes dos outros djobeurs são bastante reveladores: Didon, Sifilon, Pin-Pon, Lapochodé, Sirop, Bidjoule.

Quanto à sexualidade, o narrador de Solibo magnifique diz, de maneira satírica, que nem a negritude, nem a antilhanidade - a saber, nem Aimé Césaire, nem Édouard Glissant - souberam explorar o amor e a sexualidade.

Nossa pré-literatura foi de gritos, ódios, reivindicações, profecias para as Auroras inevitáveis
Notre pré-littérature fut de cris, de haines, de revendications, de prophéties aux Aubes inévita-

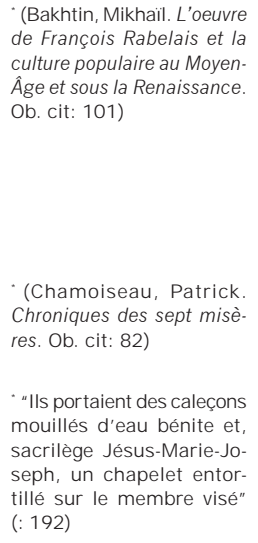

* (Bakhtin, Mikhaïl. L'oeuvre de François Rabelais et la culture populaire au MoyenÂge et sous la Renaissance. Ob. cit: 101)

* (Chamoiseau, Patrick. Chroniques des sept misè res. Ob. cit: 82)

"lls portaient des caleçons mouilles d'eau bénite et seph, un chapelet entortillé sur le membre visé" (: 192)

* (Andrade, Mário. Macunaíma: o herói sem nenhum caráter. Ob. cit.: 62)

\footnotetext{
* (Bakhtin, Mikhaïl. L'oeuvre de François Rabelais et la culture populaire au MoyenÂge et sous la Renaissance. Ob. cit: 455)
} 
* (Chamoiseau, Patrick. Solibo magnifique. Ob. cit.: 62)

"Appliquant sa nouvelle science de dorlis, il la pénétra en son mitan sans la réveiller, et passa sur le corps endormi huit heures délicieuses" (Chamoiseau, Patrick. Chroniques des sept misères. Ob. cit: 34 )

*(: 34)
[...]. No final, nada de canto ao Amor. Nenhum canto da trepada. A negritude foi castrada. E a antilhanidade não tem libido. bles [...]. Final: pas de chant sur l'Amour. Aucun chant de koké. La negritude fut castrée. Et l'antillanité n'a pas de libido *

Assim, em Chroniques des sept misères, Chamoiseau introduz a sexualidade de várias maneiras que vão do realismo mágico ao realismo grotesco. Na primeira vez em que o ato sexual é descrito, trata-se de um dorlis, personagem lúgubre que consegue penetrar em casas e em mulheres por meios sobrenaturais, quando aquelas estão fechadas e estas dormem: "Aplicando sua nova ciência de dorlis, ele a penetrou no seu interior sem acordá-la, e passou sobre o corpo adormecido oito horas deliciosas"* .

O mais engraçado, contudo, encontra-se nas explicações sobre métodos de (re)agir e impedir os ataques do dorlis, como usar "uma calcinha preta no avesso" (ou duas e, além disso, tesoura aberta debaixo do travesseiro, de acordo com o poder do dorlis). Os métodos de agir do dorlis variam:

Perde-se em conjecturas para saber se ele praticava o do sapo escondido debaixo da cama, o da formiga que passa pela fechadura, ou o do três passos para frente, três passos para trás que permite atravessar as paredes.
L'on se perd en conjectures pour savoir s'il pratiquait celle du crapaud caché sous le lit, celle de la fourmi qui passe par les serrures, ou celle des trois pas devanttrois pas derrière qui permet de traverser les murs.*

O herói do livro, Pipi, é fruto de uma noite de amor entre um dorlis e a pobre Heloísa, vítima passiva do ato sexual. Por ser filho de dorlis, é um rapaz soturno e destinado à morte, como profetiza seu pai: ele saberia falar com a jarra (que continha riquezas enterradas, conforme a lenda), mas seria engolido pela Bela. Seu amor por Anastase não se realiza; ele apenas consegue gaguejar frases incongruentes diante dela. O único período feliz de sua vida é aquele em que vive junto de Marguerite Jupiter, em que divide com ela um amor plenamente satisfeito. A descrição das acrobacias sexuais do casal, com uma lógica do excesso e do transbordamento, é simetricamente oposta à do ato sexual do dorlis, que se passa no silêncio e na passividade da mulher. A passagem, digna da melhor tradição rabelaisiana, é longa, mas necessária para perceber os diferentes aspectos desse erotismo desenfreado, desmedido: a gordura de Marguerita, a variação de posições, a repetição do ato, o excesso de prazer expresso pelos gritos 
da mulher, assim como o aspecto mágico do efeito do chá que Pipi toma para ficar em forma e transar, e também o efeito cinematográfico da cena, assistida por cinco voyeurs - os examantes, enciumados, mas admirados desse novo amante tão viril e performático.

Sem imaginar que eles estavam sendo espionados, Pipi e Marguerite passavam noites esportivas em um amor sem freios. Depois de beber o chá de bois-bandé, Pipi labutava com afinco, quase enterrado nas dobras generosas de sua amante. Quando a velha cama crioula, ao fraquejar debaixo dessa terna capoeira, rangeu a ponto de acordar as crianças, $\mathrm{o}$ casal deixou a casa para experimentar debaixo do céu estrelado, apoiado nas fachadas, nas estacas do galinheiro ou nas tábuas do chiqueiro, as ginásticas do amor vertical. Logo se jogaram na grama, rolaram pelos barrancos, e tiveram até, em uma noite em que as formigas vermelhas cobriam misteriosamente a terra, de trepar numa mangueira. Lá em cima, no tronco principal, eles fizeram, até a manhãzinha, acrobacias carnais tão perigosas, que os cinco amantes que espiavam esqueceram o ressentimento para se tornarem fãs e até torcedores. Ao relento, Marguerite dava gritos histéricos, agonizava e morria a cada noite de prazer.

Sans douter qu'ils étaient ainsi guettés, Pipi et Marguerite passaient des nuits sportives dans un amour sans chaînes. Abreuvé d'une décoction de bois-bandé, Pipi besognait ferme, presque enseveli dans les bourrelets généreux de son amante. Quand le vieux lit créole, faiblissant sous ces tendres laghias, grinça au point de réveiller les enfants, le couple quitta la case pour expérimenter le ciel étoilé, appuyé contre les façades, les piquets du poulailler ou les tôles du parc à cochons, les gymnastiques de l'amour vertical. Bientôt, ils s'abattirent dans l'herbe, roulèrent dans les ravines, et durent même, une nuit où les fourmis rouges couvraient mystérieusement la terre, grimper à un manguier. Là, sur la branche maîtresse, ils se livrèrent jusqu'à l'aube à des acrobaties charnelles tellement périlleuses que le cinq concubins guetteurs en oublièrent leur ressentiment pour se faire durant quelques heures admiratifs et même supporters. À la belle étoile Marguerite poussait des cris hystériques, agonisait et mourait chaque nuit sous les charges du plaisir

*(: 189)

Essa cena tem analogias com uma outra de Macunaíma, na qual o herói-criança se transforma em adulto para fazer amor com sua cunhada. O marido traído, em dúvida dos artifícios, assiste às acrobacias sexuais dos amantes. Por sua vez, a violência sexual, de fundo mítico, exacerba o desejo e o prazer. O caráter lúdico está presente nessa ginástica desregrada, assim como no 
* (Andrade, Mário. Macunaíma: o herói sem nenhum caráter. Ob. cit.: 11).
* (Chamoiseau, Patrick. Chroniques des sept misè res. Ob. cit: 239). uso do verbo "brincar" para designar o ato sexual. Além disso, "brincar" e "eu estou com preguiça!" são as duas expressões emblemáticas do herói, confirmando a associação feita por Georges Bataille entre erotismo e ócio.

Depois de brincarem três feitas, correram mato fora fazendo festinhas um pro outro. Depois das festinhas de cotucar, fizeram a das cócegas, depois se enterraram na areia, depois se queimaram com fogo de palha, isso foram muitas festinhas. Macunaíma pegou num tronco de copaíba e se escondeu por detrás da piranheira. Quando Sofará veio correndo, ele deu com o pau na cabeça dela. Fez uma brecha que a moça caiu torcendo de riso aos pés dele. Puxou-o por uma perna. Macunaíma gemia de gosto se agarrando no tronco gigante. Então a moça abocanhou o dedão do pé dele e engoliu. Macunaíma chorando de alegria tatuou o corpo dela com o sangue do pé. Depois retesou os músculos, se erguendo num trapézio de cipó e aos pulos atingiu num átimo o galho mais alto da piranheira. Sofará trepava atrás. O ramo fininho vergou oscilando com o peso do príncipe. Quando a moça chegou também no tope eles brincaram outra vez balanceando no céu. Depois de brincarem Macunaíma quis fazer uma festa em Sofará. Dobrou o corpo todo na violência dum puxão mas não pôde continuar, galho quebrou e ambos despencaram aos emboléus até se esborracharem no chão.*

No fim do romance, os dois personagens, Pipi e Macunaíma, morrem de forma parecida: atraídos por uma mulher aquática, de grande beleza (Man Zabyme e Uiara, respectivamente, versão crioula-antilhana e indígena-brasileira da sereia), que querem "comer" no sentido figurado de fazer amor, eles são literalmente comidos. O caçador viril se torna a caça (o caçador caçado). A fabulação, nos dois casos, é de ordem mítica porque as entidades sobrenaturais se vingam dos dois homens que ousaram enfrentá-las.

[Pipi] entendeu que Man Zabyme, nossa mais terrível diaba, a que te queima o coração com o encanto do amor antes de te comer realmente, uivando de prazer sobre teu peito aberto, acabava de carregá-lo.
[Pipi] comprit que Man Zabyme, notre plus redoutable diablesse, celle qui te grille le coeur du charme d'amour avant de te manger réellement, beuglant de plaisir au-dessus de ta poitrine ouverte, venait de l'emporter. *

Se Man Zabyme se vinga de Pipi, porque ele soube falar com a jarra; Vei, a Mãe-Sol, se vinga de Macunaíma que não quis se casar com uma de suas filhas. Macunaíma tenta resistir à 
sedução de Uiara, mas a carne é muito fraca e ele sucumbe aos seus atrativos:

Que boniteza que ela era!... Morena e coradinha que nem a cara do dia e feito o dia que vive cercado de noite, ela enrolava a cara nos cabelos curtos negros como as asas da graúna [...] Macunaíma sentiu fogo no espinhaço, estremeceu, fez pontaria, se jogou feito em cima dela, juque!*.

Quando ele tenta sair da água "estava sangrando com as mordidas pelo corpo todo, sem perna direita, sem os dedões sem os cocos-da-Bahia sem orelhas sem nariz sem nenhum dos seus tesouros" ${ }^{\prime *}$. Excessivamente desgostoso para continuar a viver, decide partir para o céu. O fim dos dois heróis é melancólico: Macunaíma se transforma na constelação da Ursa Maior, cujo brilho é inútil, e Pipi desaparece, e com ele todo o seu mundo de djobeurs. Nos dois livros, fica apenas o narrador para contar a história.

O narrador, alter-ego do próprio escritor, remete ao contador popular. Walter Benjamin distingue dois tipos de narrador: o romancista, escrevendo na solidão do seu escritório, não tem contato com o leitor, enquanto o contador se dirige às pessoas para trocar sua experiência, dar-lhes conselhos e transmitir-lhes um conhecimento. Chamoiseau e Andrade evocam, em seus livros, o contador popular que fala para interlocutores imaginários, como se estivesse presente diante deles. Por isso, o emprego do vocativo "Messieurs et dames de la compagnie" que prolifera em Chroniques des sept misères, e "minha gente", de Macunaíma, assim como os dêiticos: "E o homem sou eu, minha gente, e eu fiquei pra vos contar a história. Por isso que vim aqui”** Esse narrador irreverente procede como o narrador da gesta rabelaisiana, que interpela o leitor diversas vezes com vocativos do tipo: "Bonnes gens, Beuveurs tresillustres, et vous Goutteuz tresprecieux...”*.

No que se refere à língua, há certa semelhança entre a situação de diglossia nas Antilhas e a da França no século XVI, com a coexistência de duas línguas: o latim, língua escrita por excelência, e o francês, língua vernácula falada, língua "da vida, língua dos gêneros inferiores (fábulas, farsas, cris de Paris etc. na sua maioria cômicos); ela era, enfim, a língua do livre falar da praça pública"*. Subalterna como o crioulo, para tornar-se língua literária, o francês teve de passar por um processo de defesa representado pela política lingüística da Pléiade, cujo livro emblemático é La défense et l'illustration
* (Andrade, Mário. Macu. naíma: o herói sem nenhum caráter. Ob. cit.: 62)

* (: 143)

* (: 148)

* (Rabelais, François. Pantagruel. Paris: GF-Flammarion, 1993: 37)

* (Bakhtin, Mikhaïl. L'oeuvre de François Rabelais et la culture populaire au MoyenÂge et sous la Renaissance. Ob. cit.: 462). 
* (Chamoiseau, Patrick. Chroniques des sept misères. Ob. cit: 201)

de la langue française, de Du Bellay. O Renascimento, segundo Bakhtin, "marca o fim da dualidade das línguas e a substituição lingüística. Muito do que foi possível nesta única e excepcional época da vida da literatura francesa e da língua tornou-se impossível em todas as épocas posteriores"*. Há, pois, uma analogia com a situação das Antilhas: o crioulo continua como língua da família, do trabalho no campo, da intimidade e dos "gêneros inferiores", como os contos, as adivinhações e as canções. É preciso, contudo, destacar uma diferença fundamental: a literatura antilhana, que se consagra em centros de legitimação como Paris, é escrita em francês. Assim, a oralidade crioula que alimenta os romances de Patrick Chamoiseau tende a desaparecer - como ele, aliás, mostra com certa nostalgia em Solibo Magnifique - e não se dará a substituição, criando uma literatura em língua crioula, como as línguas vernáculas européias fizeram a partir do século XVI.

O conflito lingüístico é representado de maneira paródica e também satírica por dois interlocutores antagônicos, que não conseguem se compreender: de um lado, Aimé Césaire, poeta da negritude e prefeito de Fort-de-France, transformado em personagem; do outro, Pipi, djobeur inculto, que resmunga, balbucia, porque só fala o crioulo. Pipi, o milagroso jardineiro, que tinha tido um formidável sucesso com sua horta, não compreende as questões feitas pelo prefeito, que quer conhecer a motivação de seu trabalho.

Entendendo vagamente o sentido da pergunta, Pipi desta vez esqueceu os cabelos, o francês, a roupa, para dizer rápido: - Ebyen misié limé, séti manmay la té fin, danne!...

Frase que, de noite, no jornal televisivo, depois de um programa sobre o Loir-et-Cher, o locutor traduziu por: Senhor prefeito, as crianças tinham tanta fome !... Por isso, no mercado, durante um tempão, todo mundo pensou que o Pipi era doutor na língua da França.
Percevant vaguement le sens de la question, Pipi cette fois oublia ses cheveux, son français, sa tenue, pour souffler rapidement: - Ebyen misié limé, séti manmay la té fin, danne!...

Phrase que le soir au journal télévisé, après un dossier sur le Loir-et-Cher, le speaker traduisit par: Monsieur le Maire, les enfants avaient tellement faim!... C'est pourquoi au marché, durant une charge de temps, tout le monde crut Pipi docteur en langage de France. 
Algo semelhante aconteceu no Brasil, como mostrou Roger Bastide em artigo publicado em 1946, no qual estabelece um paralelismo entre o trabalho de Mário de Andrade, o de Rabelais e o de Du Bellay. O projeto dos modernistas era tornar literária a língua de todos os dias, a língua que era falada pelos brasileiros, sem se submeter ao modelo português. No capítulo intitulado "Carta às Icamiabas", paródia da língua pedante e retórica, que ainda era utilizada por certos escritores no início do século XX, Macunaíma faz um verdadeiro inventário etnográfico de todos os usos bizarros da civilização às suas amigas Amazonas. A originalidade lingüística do país é assim explicada por Macunaíma/Mário de Andrade:

Nas conversas, utilizam-se os paulistanos dum linguajar bárbaro e multifário, crasso da feição e impuro na vernaculidade, mas que não deixa de ter o seu sabor e força nas apóstrofes, e também nas vozes do brincar. Destas e daquelas nos inteiramos, solícito; e nos será grata empresa vô-las ensinarmos aí chegado. Mas si de tal desprezível língua se utilizam na conversação os naturais desta terra, logo que tomam a pena, se despojam de tanta asperidade, e surge o Homem Latino, de Lineu, exprimindo-se numa outra linguagem, mui próxima da vergiliana, no dizer de um panegirista, meigo idioma, que, com imperecível galhardia, se intitula: língua de Camões!*

* (: 148)

Essa língua impura falada pelos paulistanos remete àquela que o narrador diz ter utilizado para escrever seu livro "cantando na fala impura as frases e os casos de Macunaíma”* . A voz de Macunaíma em "Carta às Icamiabas", identifica-se com a voz do autor, que, aliás, confessa alegremente ter praticado o plágio mais desavergonhado, uma vez que copiou passagens inteiras de determinados escritores (Rui Barbosa, Coelho Neto). Assim, pastiche, paródia e sátira se juntam para subverter a situação lingüística.

Não se deve, no entanto, cair na armadilha de pensar que Mário de Andrade e Patrick Chamoiseau escrevem na língua falada, o que certamente é irrealizável, tendo cada uma - língua escrita e língua oral - sua própria gramática. Não se trata de uma língua real, efetivamente falada, mas de uma estilística da oralidade ou, como escreveu Mário de Andrade em carta a Rosário Fusco em 1928, Macunaíma foi escrito "em língua artificial, como é de fato toda língua escrita", acrescentando ter feito "uma estilização lírica puramente individualista da fala brasileira"*. Isso corresponde ao "français chamoisisé",

* (Andrade, Mário. Macu-
naíma: o herói sem nenhum caráter. Ob. cit.: 78) 
*(Bakhtin, Mikhaïl. L'oeuvre de François Rabelais et la culture populaire au MoyenÂge et sous la Renaissance. Ob. cit.: 420)
* (Andrade, Mário. Macunaíma: o herói sem nenhum caráter. Ob. cit.: 91) expressão criada por Milan Kundera para designar a língua utilizada por Chamoiseau, que se apropria de uma certa poética do crioulo, sem escrever em francês crioulizado, crioulo afrancesado ou coisa que o valha.

Essa língua livre pode recorrer a expressões sem significação clara, somente pelo prazer de uma sonoridade, de um gracejo, de um jogo de palavras, de um coq-à-l'âne, que é segundo Bakhtin, "uma espécie de recriação de palavras e de coisas deixadas em liberdade, livres da opressão do sentido, da lógica, da hierarquia verbal”*. Rabelais brinca com a linguagem com verve, irreverência, satisfação lúdica levada ao exagero. Em Pantagruel, há algumas cenas antológicas: a do écolier limousin confuso entre duas línguas (seu patuá natal e o latim que ele não domina), a do encontro de Panurge, que fala a Pantagruel em 14 línguas diferentes (das quais o leitor compreende apenas duas ou três), a das listas de livros, a das cartas de Grandgousier, e tantas outras.

Em Macunaíma e Chroniques des sept misères, as frases sem significação remetem, em geral, ao mundo indígena, à fauna e à flora locais, ao quimbois ${ }^{4}$ ès receitas mágicas. Exemplo de frase sem significação repetida por Macunaíma: "Tetápe, dzónanei pemonéite hêhê zeténe netaíte"*. Desde a experiência revolucionária dos modernistas em geral, e em particular de Mário de Andrade, o português do Brasil se tornou mais flexível, permitindo a eclosão de escritores como Guimarães Rosa. Esse livro, porém, permanece único: Mário de Andrade temia que as gerações posteriores tomassem Macunaíma como modelo a ser imitado, mas isso não aconteceu. Já em Chroniques des sept miseres passagens em crioulo, sem tradução, são acrescentadas no fim do romance em forma de paratexto: os gritos do djob e a canção de Kouli. O leitor francês fica um pouco confuso sobretudo diante da contaminação do francês pelo crioulo, da liberdade no uso da língua oral, prática que não se inscreve na tradição literária francesa, salvo algumas exceções como Louis-Ferdinand Céline e Raymond Queneau.

A tradução desse gênero de romance implica muitos problemas. Jacques Thiériot enfrentou o desafio de traduzir $M a-$ cunaíma, um verdadeiro esforço que exigiu uma trans-criação.

${ }^{4}$ Quimbois designa, nas Pequenas Antilhas de língua francesa, as práticas de medicina tradicional africana, associadas também à feitiçaria; quimboiseur é a pessoa que o pratica. 
Publicou a primeira tradução em 1979 e fez uma revisão para a edição crítica de 1996, que recebeu vários artigos que ajudam a elucidar o romance para os leitores franceses. O caráter rabelaisiano do livro foi evidenciado pelo trabalho da tradução, cujos principais procedimentos consistiram no uso de termos arcaicos - aigue no lugar de eau, bren no lugar de excréments, papegai no lugar de perroquet, foultitude de/moult em vez de beaucoup - e no estilo das frases - "Dès la prime enfance, il fit des choses bien épouvantables"*. Por outro lado, o uso de certas palavras caribenhas aproxima Mário de Andrade de Patrick Chamoiseau e de outros escritores antilhanos: ajoupa, carbet, tafia, et cric! Outras expressões, se bem que existentes em francês, foram postas em circulação particularmente por romancistas antilhanos: dame-jeanne, cochoncetés, mauvaisetés. A ortografia fonética introduzida por Queneau e utilizada por Chamoiseau foi empregada pelo tradutor de Macunaíma: ouisqui no lugar de whisky, bisenesse no lugar de business.

As obras literárias de Mário de Andrade e de Patrick Chamoiseau, apesar de separadas por mais de meio século de distância, tem semelhanças devido a seu caráter a um só tempo sacralizante e dessacralizante. Segundo Édouard Glissant, a função de dessacralização é uma "função de heresia, de análise intelectual, que é de desmontar as engrenagens de um sistema dado, de colocar a nu os mecanismos fechados, de desmistificar"** Esse lado dessacralizador passa sobretudo pelo riso, que se opõe à cultura oficial, ao tom sério do poder político e religioso. Os políticos, a televisão, a imprensa, a polícia, enfim, todo o mundo da ordem se torna objeto de sátira e é ridicularizado. A façanha agrícola de Pipi, o jardineiro-milagroso, é disputada por uns e por outros.

Os partidos políticos independentistas e outros bandos de negros revoltados concederam-lhe medalhas, convidaram-no para encontros em que, da tribuna de honra, ele escutava pacientemente discursos incompreensíveis [...]. France-Antilles publicou sua foto no lugar reservado geralmente para estupradores e assassinos.

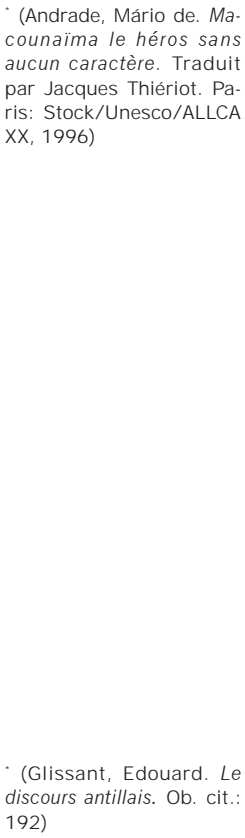

(Andrade, Mário de. Ma counaïma le héros sans aucun caractère. Traduit par Jacques Thiériot. $\mathrm{Pa}$ ris: Stock/Unesco/ALLCA $X X, 1996)$

* (Glissant, Edouard. Le (O) 192) 
* (Bakhtin, Mikhaïl. L'oeuvre de François Rabelais et la culture populaire au Moyen Âge et sous la Renaissance. Ob. cit.: 12)

* (Glissant, Edouard. Le dis cours antillais. Ob. cit.: 192)

${ }^{*}(:$ 192)
Ambos os autores se nutrem da cultura cômica popular, constituída de "festejos públicos do carnaval, ritos e cultos cômicos especiais, bufões e sots, gigantes, anões e monstros, palhaços de natureza e condições diversas, literatura paródica vasta e variada"*. A obra deles, todavia, também tem um caráter sacralizante, concebido por Glissant como uma "função de reunião da comunidade em torno de seus mitos, de suas crenças, de seu imaginário ou de sua ideologia"*, uma vez que, apropriandose da cultura popular, normalmente abandonada como objeto folclórico, e incorporando-a à literatura nacional, o escritor legitima as tradições. O papel do escritor dessas novas literaturas nacionais é, portanto, duplo, pois deve "aliar o mito à desmistificação, a inocência à malícia adquirida”* . 


\section{Eurídice Figueiredo}

Doutora em Língua e Literatura Francesas pela UFRJ (1988), é pesquisadora do CNPq e professora de Literaturas Francófonas e Literatura Comparada na UFF, onde coordena o Grupo de Pesquisa "Relações literárias interamericanas". Organizou o livro Conceitos de literatura e cultura (EdUFF/Editora UFJF, 2005) e publicou Construções de identidades pós-coloniais na literatura antilhana (EdUFF, 1998), além de inúmeros artigos em obras coletivas e em revistas especializadas.

\section{Resumo}

O objetivo deste artigo é fazer uma análise comparativa de dois romances, Macunaíma, de Mário de Andrade, e Chronique des sept misères, de Patrick Chamoiseau, a fim de rastrear os principais procedimentos usados, sobretudo os relativos ao realismo grotesco, que os inserem na grande tradição cômica e popular de Rabelais, tão bem estudada por Mikhail Bakhtin.

\begin{abstract}
I propose a comparative analysis of two novels, Macunaima, by Mário de Andrade, and Chronique des sept misères, by Patrick Chamoiseau, in order to point out the main common aspects concerning the grotesque realism which reveal that both authors belong to the Rabelaisian comical and popular tradition, that has been studied by Mikhaïl Bakhtin.
\end{abstract}

\section{Résumé}

L'objectif de cet article est de faire une analyse comparative de deux romans, Macounaïma, de Mário de Andrade, et Chronique des sept misères, de Patrick Chamoiseau, afin de dégager les principaux procédés utilisés, surtout ceux qui concernent le réalisme grotesque, qui les place dans la grande tradition comique et populaire de Rabelais, très bien étudiée par $\mathrm{M}$. Bakhtine.

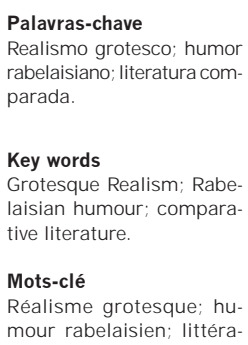

Recebido em $15 / 05 / 2005$

Aprovado em $20 / 06 / 2005$ 